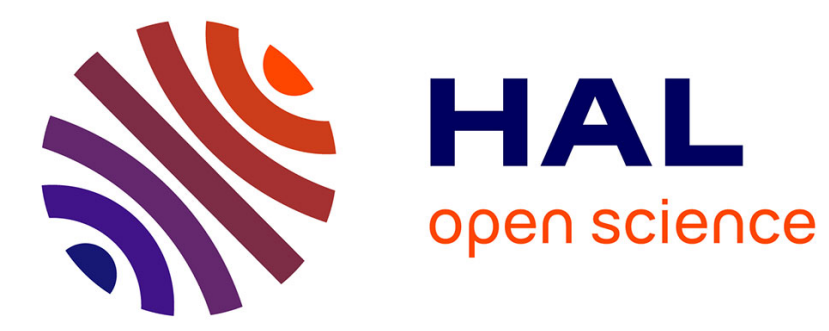

\title{
Portal infusion of a selective serotonin reuptake inhibitor enhances hepatic glucose disposal in conscious dogs
} \author{
Mary Courtney Moore, Catherine A. Di Costanzo, Dominique Dardevet,
} Margaret Lautz, Ben Farmer, Doss W. Neal, Alan D. Cherrington

\section{- To cite this version:}

Mary Courtney Moore, Catherine A. Di Costanzo, Dominique Dardevet, Margaret Lautz, Ben Farmer, et al.. Portal infusion of a selective serotonin reuptake inhibitor enhances hepatic glucose disposal in conscious dogs. AJP - Endocrinology and Metabolism, 2004, 287 (6), pp.E1057-E1063. 10.1152/ajpendo.00313.2004 . hal-02676919

\section{HAL Id: hal-02676919 \\ https://hal.inrae.fr/hal-02676919}

Submitted on 31 May 2020

HAL is a multi-disciplinary open access archive for the deposit and dissemination of scientific research documents, whether they are published or not. The documents may come from teaching and research institutions in France or abroad, or from public or private research centers.
L'archive ouverte pluridisciplinaire HAL, est destinée au dépôt et à la diffusion de documents scientifiques de niveau recherche, publiés ou non, émanant des établissements d'enseignement et de recherche français ou étrangers, des laboratoires publics ou privés. 
Mary Courtney Moore, Catherine A. DiCostanzo, Dominique Dardevet, Margaret Lautz, Ben Farmer, Doss W. Neal and Alan D. Cherrington

Am J Physiol Endocrinol Metab 287:1057-1063, 2004. First published Aug 17, 2004;

doi:10.1152/ajpendo.00313.2004

You might find this additional information useful...

This article cites 36 articles, 13 of which you can access free at:

http://ajpendo.physiology.org/cgi/content/full/287/6/E1057\#BIBL

This article has been cited by 3 other HighWire hosted articles:

The selective serotonin reuptake inhibitor sertraline enhances counterregulatory responses to hypoglycemia

N. M. Sanders, C. W. Wilkinson, G. J. Taborsky Jr., S. Al-Noori, W. Daumen, A. Zavosh and D. P. Figlewicz

Am J Physiol Endocrinol Metab, May 1, 2008; 294 (5): E853-E860.

[Abstract] [Full Text] [PDF]

Portal 5-hydroxytryptophan infusion enhances glucose disposal in conscious dogs

M. C. Moore, K. Kimura, H. Shibata, T. Honjoh, M. Saito, C. A. Everett, M. S. Smith and A. D. Cherrington

Am J Physiol Endocrinol Metab, August 1, 2005; 289 (2): E225-E231.

[Abstract] [Full Text] [PDF]

Interaction of a selective serotonin reuptake inhibitor with insulin in the control of hepatic glucose uptake in conscious dogs

M. C. Moore, C. A. DiCostanzo, D. Dardevet, M. Lautz, B. Farmer and A. D. Cherrington Am J Physiol Endocrinol Metab, March 1, 2005; 288 (3): E556-E563.

[Abstract] [Full Text] [PDF]

Updated information and services including high-resolution figures, can be found at:

http://ajpendo.physiology.org/cgi/content/full/287/6/E1057

Additional material and information about AJP - Endocrinology and Metabolism can be found at: http://www.the-aps.org/publications/ajpendo

This information is current as of September 3, 2010 .

AJP - Endocrinology and Metabolism publishes results of original studies about endocrine and metabolic systems on any level of organization. It is published 12 times a year (monthly) by the American Physiological Society, 9650 Rockville Pike, Bethesda MD 20814-3991. Copyright @ 2004 by the American Physiological Society. ISSN: 0193-1849, ESSN: 1522-1555. Visit our website at http://www.the-aps.org/. 


\title{
Portal infusion of a selective serotonin reuptake inhibitor enhances hepatic glucose disposal in conscious dogs
}

\author{
Mary Courtney Moore, ${ }^{1,2}$ Catherine A. DiCostanzo, ${ }^{1}$ Dominique Dardevet, ${ }^{1}$ \\ Margaret Lautz, ${ }^{1}$ Ben Farmer, ${ }^{1}$ Doss W. Neal, ${ }^{1}$ and Alan D. Cherrington ${ }^{1,2}$ \\ ${ }^{1}$ Department of Molecular Physiology and Biophysics, and ${ }^{2}$ Diabetes Research and \\ Training Center, Vanderbilt University School of Medicine, Nashville, Tennessee 37232
}

Submitted 15 July 2004; accepted in final form 10 August 2004

\begin{abstract}
Moore, Mary Courtney, Catherine A. DiCostanzo, Dominique Dardevet, Margaret Lautz, Ben Farmer, Doss W. Neal, and Alan D. Cherrington. Portal infusion of a selective serotonin reuptake inhibitor enhances hepatic glucose disposal in conscious dogs. Am J Physiol Endocrinol Metab 287: E1057-E1063, 2004. First published August 17, 2004; doi:10.1152/ajpendo.00313.2004.- Intraportal delivery of serotonin enhanced net hepatic glucose uptake (NHGU) during a hyperinsulinemic hyperglycemic clamp, but serotonin elevated catecholamines and can cause gastrointestinal distress. We hypothesized that the selective serotonin reuptake inhibitor (SSRI) fluvoxamine would enhance NHGU without side effects. Arteriovenous difference and tracer $\left(\left[3-{ }^{3} \mathrm{H}\right]\right.$ glucose $)$ techniques were used in conscious 42-h-fasted dogs. Experiments consisted of equilibration ( -120 to $-30 \mathrm{~min})$, basal ( -30 to $0 \mathrm{~min}$ ), and experimental (EXP; 0-270 min) periods. During EXP, somatostatin, fourfold basal intraportal insulin, basal intraportal glucagon, and peripheral glucose (to double the hepatic glucose load) were infused. Saline (SAL) was infused intraportally during $0-90 \mathrm{~min}$ (P1), and fluvoxamine was infused intraportally at $0.5,1$, and $2 \mu \mathrm{g} \cdot \mathrm{kg}^{-1} \cdot \mathrm{min}^{-1}$ from 90 to 150 (P2), 150 to $210(\mathrm{P} 3)$, and 210 to $270(\mathrm{P} 4) \mathrm{min}$, respectively, in the FLUV group $(n=8)$. The SAL group $(n=9)$ received intraportal saline during $0-270 \mathrm{~min}$. NHGU in SAL was $13.9 \pm 1.7$ and $17.0 \pm$ $2.0 \mu \mathrm{mol} \cdot \mathrm{kg}^{-1} \cdot \mathrm{min}^{-1}$ in P3-P4, respectively, while NHGU in FLUV averaged $19.7 \pm 2.8$ and $26.6 \pm 3.0 \mu \mathrm{mol} \cdot \mathrm{kg}^{-1} \cdot \mathrm{min}^{-1}(P<0.05 \mathrm{vs}$. SAL). Net hepatic carbon retention was greater $(P<0.05)$ in FLUV than in SAL $(17.6 \pm 2.6$ vs. $13.9 \pm 2.7$ and $23.8 \pm 3.0$ vs. $14.4 \pm 3.3$ $\mu \mathrm{mol} \cdot \mathrm{kg}^{-1} \cdot \mathrm{min}^{-1}$ in $\mathrm{P} 3-\mathrm{P} 4$, respectively), and final hepatic glycogen concentrations were $50 \%$ greater in FLUV $(P<0.005)$. Nonhepatic glucose uptake was greater in SAL than in FLUV at $270 \mathrm{~min}$ $(P<0.05)$. Catecholamine concentrations remained basal, and the animals evidenced no distress. Thus fluvoxamine enhanced NHGU and hepatic carbon storage without raising circulating serotonin concentrations or causing stress, suggesting that hepatic-targeted SSRIs might be effective in reducing postprandial hyperglycemia in individuals with diabetes or impaired glucose tolerance.
\end{abstract}

glycemia; liver; portal vein; hepatic glucose uptake; nonhepatic glucose uptake

INTRAPORTAL INFUSION OF SEROTONIN (5-hydroxytryptamine, or 5-HT) enhanced net hepatic glucose uptake (NHGU) in conscious dogs during a hyperinsulinemic hyperglycemic clamp (22). These findings suggest that 5-HT might play a role in limiting postprandial glycemic excursions in individuals with type 2 diabetes or impaired glucose tolerance. Good control of glycemia has been documented to reduce the risk of diabetesrelated complications (35); because diabetes is a progressive

Address for reprint requests and other correspondence: M. C. Moore, Dept. of Molecular Physiology \& Biophysics, 702 Light Hall, Vanderbilt Univ. School of Medicine, Nashville, TN 37232-0615 (E-mail: genie.moore @ vanderbilt.edu).

http://www.ajpendo.org

0193-1849/04 \$5.00 Copyright @ 2004 the American Physiological Society

The costs of publication of this article were defrayed in part by the payment of page charges. The article must therefore be hereby marked "advertisement"
in accordance with 18 U.S.C. Section 1734 solely to indicate this fact.

disease, there is a need for a variety of pharmacological tools for diabetes treatment. Thus the effects of 5-HT on hepatic and whole body glucose metabolism are intriguing and invite further study.

Plasma concentrations of catecholamines and cortisol increased during the portal 5-HT infusion (22), and high concentrations of 5-HT in humans are well known to be associated with abdominal cramping and diarrhea $(3,4)$. These side effects limit the administration of 5-HT itself in physiological studies, but there are a variety of agents available that enhance or prolong endogenous 5-HT activity.

The selective serotonin reuptake inhibitors (SSRIs) provide a mechanism for enhancing endogenous 5-HT concentrations without delivering 5-HT itself, thus reducing the side effects associated with high circulating levels of 5-HT. The literature does not provide a definite answer regarding the effects of the SSRIs on glycemia. Bolus intraperitoneal injection of the SSRIs fluoxetine and fluvoxamine into mice produced a doserelated hyperglycemia (38). However, very large doses were used (5-20 mg/kg in a single bolus dose compared with a therapeutic dose of $\sim 0.3 \mathrm{mg} \cdot \mathrm{kg}^{-1} \cdot \mathrm{day}^{-1}$ for fluoxetine and $1.5-4 \mathrm{mg} \cdot \mathrm{kg}^{-1} \cdot \mathrm{day}^{-1}$ for fluvoxamine), and hyperglycemia did not occur with either drug at the $5 \mathrm{mg} / \mathrm{kg}$ dose. Conversely, intraperitoneal administration of fluoxetine or sertraline (also at very high doses, $30 \mathrm{mg} / \mathrm{kg}$ for each drug) reduced glycemia without altering insulin concentrations in both normoglycemic and alloxan-diabetic mice (11). Furthermore, fluoxetine treatment for 8 wk significantly reduced basal insulin concentrations without altering basal glucose concentrations in both sham-operated and 90\%-pancreatectomized rats and also increased glucose disposal during a hyperinsulinemic euglycemic clamp in both groups without changing food intake or body weight significantly (28). Taken together, these findings suggest that the SSRIs might have insulin-like or insulinsensitizing effects independent of their known ability to reduce body weight $(33,37)$. Therefore, we examined the effect of an increase in endogenous hepatic 5-HT, brought about by an intraportal infusion of fluvoxamine, on NHGU and total body glucose disposal $\left(\mathrm{R}_{\mathrm{d}}\right)$ in conscious dogs during a hyperinsulinemic hyperglycemic clamp.

\section{RESEARCH DESIGN AND METHODS}

Animals and surgical procedures. Studies were carried out on 17 conscious 42-h-fasted adult mongrel dogs of either sex with a mean weight of $23.4 \pm 1.3 \mathrm{~kg}$. Diet and housing were as previously 
described (27), and the protocol was approved by the Vanderbilt University Institutional Animal Care and Use Committee. National Institutes of Health guidelines for the care and use of laboratory animals were followed in all respects, and the housing facility met the standards of, and is regularly inspected by, the United States Department of Agriculture. The 42-h-fast was used because it reduces hepatic glycogen concentrations to a stable minimum (15) and because it causes the liver to become a net consumer rather than a producer of lactate [resembling the metabolic state of the overnightfasted human $(19,20)]$.

Approximately 16 days before study, each dog underwent a laparotomy for placement of ultrasonic flow probes (Transonic Systems, Ithaca, NY) around the portal vein and the hepatic artery, as well as for insertion of silicone rubber catheters for sampling in a hepatic vein, the portal vein, and a femoral artery and for infusion into a splenic and a jejunal vein, as described in detail elsewhere $(23,27)$. Criteria for study were as previously described $(23,27)$.

On the morning of the study, catheters and flow probe leads were exteriorized from their subcutaneous pockets $(23,27)$. The splenic and jejunal catheters were used for intraportal infusion of insulin (Eli Lilly, Indianapolis, IN), glucagon (GlucaGen; Bedford Laboratories, Bedford, $\mathrm{OH}$ ), and fluvoxamine maleate (Tocris, Ellisville, MO). Angiocaths (Deseret Medical, Sandy, UT) were inserted into three peripheral veins.

Experimental design. Each experiment consisted of a 90-min equilibration period ( -120 to $-30 \mathrm{~min})$, a $30-\mathrm{min}$ basal period ( -30 to 0 $\mathrm{min}$ ), and a $270-\mathrm{min}$ experimental period (0 to $270 \mathrm{~min}$ ) divided into four subperiods (P1, 0-90 min; P2, 90-150 min; P3, 150-210 min, and $\mathrm{P} 4,210-270 \mathrm{~min}$ ). At $-120 \mathrm{~min}$, a primed continuous infusion of $\left[3-{ }^{3} \mathrm{H}\right]$ glucose and a continuous infusion of indocyanine green (ICG) dye were begun in all dogs (22). At $0 \mathrm{~min}$, a constant peripheral infusion of somatostatin $\left(0.8 \mu \mathrm{g} \cdot \mathrm{kg}^{-1} \cdot \mathrm{min}^{-1}\right)$ was begun to suppress endogenous insulin and glucagon secretion. Insulin was infused intraportally at $1.2 \mathrm{mU} \cdot \mathrm{kg}^{-1} \cdot \mathrm{min}^{-1}$ (4-fold basal), and glucagon $(0.55$ $\left.\mathrm{ng} \cdot \mathrm{kg}^{-1} \cdot \mathrm{min}^{-1}\right)$ was replaced intraportally in basal amounts. In addition, a primed continuous variable-rate infusion of $50 \%$ dextrose was begun through a peripheral vein to raise and maintain the hepatic glucose load to a rate twofold basal. During P1, all dogs received intraportal saline infusion. At the end of $\mathrm{P} 1$, the dogs were divided into two groups. In the SAL group $(n=9)$, the intraportal saline infusion continued for the remainder of the study. In the FLUV group $(n=8)$, fluvoxamine was infused into the portal vein at $0.5,1$, and 2 $\mu \mathrm{g} \cdot \mathrm{kg}^{-1} \cdot \min ^{-1}$ during $\mathrm{P} 2, \mathrm{P} 3$, and P4, respectively. The intraportal infusion allowed us to target the liver specifically with the fluvoxamine. Fluvoxamine was chosen because of its selectivity for the serotonin receptor over other monoamine receptors (34) and its extensive $(\sim 45 \%)$ first-pass extraction by the liver (36), which reduced the potential for circulating fluvoxamine to impact on muscle or adipose glucose uptake. In addition, the dosage was kept low (a total of 0.21 $\mathrm{mg} / \mathrm{kg}$ over $3 \mathrm{~h}$ compared with a usual daily therapeutic dose of 2-4 $\mathrm{mg} / \mathrm{kg}$ ) to reduce the potential for systemic effects of fluvoxamine.

Femoral artery, portal vein, and hepatic vein blood samples were taken every 15-30 min throughout the study as previously described $(23,27)$. Arterial blood samples were also taken every 5 min throughout the experimental period to monitor the glucose level $(23,27)$. After completion of each experiment, the animal was anesthetized, and biopsies of liver and skeletal muscle (gracilis) were immediately freeze-clamped in situ. The animal was then euthanized with an overdose of pentobarbital sodium.

Processing and analysis of samples. Hematocrit, blood glucose, lactate, and glycerol, and plasma glucose, NEFA, insulin, glucagon, cortisol, catecholamines, and $\left[{ }^{3} \mathrm{H}\right]$ glucose were measured as described previously $(23,27,31)$. 5-HT concentrations were determined on whole blood by an HPLC-amperometric assay (29) with a coefficient of variation of 4\%, as previously described (22). Tissue glycogen concentrations were measured by the method of Keppler and Decker (21).
Calculations and data analysis. Hepatic blood flow was measured using ultrasonic flow probes and by use of ICG extraction. The two methods yielded similar results, but the data reported here were calculated with the ultrasonic-determined flows, because their measurement did not require an assumption regarding the relative contribution of arterial and portal flow to total hepatic blood flow.

The rate of glucose delivery to the liver (or hepatic glucose load), net hepatic substrate balance, net hepatic fractional substrate extraction, net hepatic carbon retention, hepatic sinusoidal insulin and glucagon concentrations, nonhepatic glucose uptake (non-HGU), glucose turnover, and unidirectional hepatic glucose uptake were calculated as described previously $(26,27)$. During the 1 st $\mathrm{h}$ of glucose infusion, the non-HGU was corrected for the glucose required to fill the pool, using a pool fraction of 0.65 (9) and assuming that the volume of distribution for glucose equaled the volume of the extracellular fluid or $\sim 22 \%$ of the dog's weight (32). For all glucose balance calculations, glucose concentrations were converted from plasma to blood values by using correction factors (ratio of the blood to the plasma concentration), as previously established in our laboratory $(17,18,27)$.

Statistical analysis. All data are presented as means \pm SE. Time course data were analyzed with repeated-measures ANOVA, and Tukey's test was used for post hoc comparisons (SigmaStat; Jandel Scientific, Chicago, IL). Statistical significance was accepted at $P<$ 0.05 .

\section{RESULTS}

5-HT, insulin, glucagon, cortisol, and catecholamine concentrations. Arterial and portal blood 5-HT concentrations and net hepatic 5-HT output remained basal in both groups throughout all study periods and did not differ significantly between groups at any time (Table 1).

The plasma insulin levels increased approximately three- to fourfold and remained stable during P1-P4 in both groups (Table 1). Arterial and hepatic sinusoidal plasma glucagon concentrations were basal and indistinguishable in both groups throughout the experiments (Table 1). In both groups, the arterial plasma cortisol and epinephrine concentrations declined from basal during P1-P4. The cortisol and catecholamine concentrations did not differ between groups at any time (Table 1).

Hepatic blood flow, blood glucose concentrations, and hepatic glucose load. Portal vein blood flow decreased significantly in both groups during P1 as a response to somatostatin infusion and did not change significantly thereafter (Table 2). There was a concomitant increase in hepatic artery flow. As a consequence, total hepatic blood flow was relatively stable throughout the experiments within each group. There were no significant differences in blood flow between groups.

Arterial blood glucose levels in both groups increased from a basal value of $4.5 \pm 0.1$ to $\sim 9.3 \pm 0.1 \mathrm{mmol} / \mathrm{l}$ during all experimental periods (Fig. 1). The hepatic glucose loads (HGL) did not differ significantly between groups at any time (Fig. 1). In SAL, the HGL increased from $143 \pm 9$ (basal) to $275 \pm 15 \mu \mathrm{mol} \cdot \mathrm{kg}^{-1} \cdot \mathrm{min}^{-1}$ in $\mathrm{P} 1-\mathrm{P} 4$, and in FLUV, HGL increased from $155 \pm 11$ to $286 \pm 10 \mu \mathrm{mol} \cdot \mathrm{kg}^{-1} \cdot \mathrm{min}^{-1}$.

Net hepatic glucose balance and net hepatic fractional glucose extraction. The groups exhibited a similar rate of net hepatic glucose output during the basal period. Coincident with the start of the experimental period, they switched from net production to net uptake, with the rates being no different between groups during P1 (12.9 \pm 2.1 and $15.0 \pm 2.3$ 
Table 1. Serotonin concentrations and net hepatic balance and hormone concentrations

\begin{tabular}{|c|c|c|c|c|c|}
\hline \multirow{2}{*}{$\begin{array}{l}\text { Parameter } \\
\text { and Group }\end{array}$} & \multirow[b]{2}{*}{ Basal Period } & \multicolumn{4}{|c|}{ Experimental Period } \\
\hline & & P1 & P2 & P3 & P4 \\
\hline \multicolumn{6}{|c|}{ Arterial blood 5-HT, $\mu g / l$} \\
\hline SAL & $1,003 \pm 169$ & $928 \pm 151$ & $937 \pm 171$ & $919 \pm 165$ & $801 \pm 186$ \\
\hline FLUV & $821 \pm 127$ & $799 \pm 82$ & $868 \pm 95$ & $826 \pm 92$ & $788 \pm 86$ \\
\hline \multicolumn{6}{|c|}{ Portal blood 5-HT, $\mu \mathrm{g} / \mathrm{l}$} \\
\hline SAL & $1,132 \pm 194$ & $1,082 \pm 170$ & $1,043 \pm 174$ & $1,022 \pm 169$ & $926 \pm 157$ \\
\hline FLUV & $1,028 \pm 195$ & $1,043 \pm 141$ & $974 \pm 134$ & $918 \pm 124$ & $877 \pm 116$ \\
\hline \multicolumn{6}{|c|}{ Net hepatic 5-HT balance, $\mu \mathrm{g} \cdot \mathrm{kg}^{-1} \cdot \mathrm{min}^{-1}$} \\
\hline SAL & $0.6 \pm 1.5$ & $-0.4 \pm 2.0$ & $1.2 \pm 0.7$ & $1.5 \pm 0.7$ & $2.7 \pm 0.9$ \\
\hline FLUV & $2.3 \pm 2.1$ & $2.3 \pm 1.5$ & $0.8 \pm 1.4$ & $1.8 \pm 1.8$ & $0.9 \pm 1.8$ \\
\hline \multicolumn{6}{|c|}{ Arterial plasma insulin, pmol/l } \\
\hline SAL & $51 \pm 7$ & $119 \pm 13 *$ & $120 \pm 10 *$ & $135 \pm 11 *$ & $132 \pm 14^{*}$ \\
\hline FLUV & $47 \pm 7$ & $117 \pm 12 *$ & $124 \pm 9 *$ & $136 \pm 10 *$ & $139 \pm 9 *$ \\
\hline \multicolumn{6}{|c|}{ Hepatic sinusoidal insulin, $\mathrm{pmol} / \mathrm{l}$} \\
\hline SAL & $136 \pm 21$ & $449 \pm 55^{*}$ & $497 \pm 54 *$ & $472 \pm 41 *$ & $438 \pm 32 *$ \\
\hline FLUV & $114 \pm 13$ & $406 \pm 41^{*}$ & $425 \pm 46^{*}$ & $424 \pm 42 *$ & $452 \pm 44^{*}$ \\
\hline \multicolumn{6}{|c|}{ Arterial plasma glucagon, $n g / l$} \\
\hline SAL & $41 \pm 4$ & $39 \pm 4$ & $36 \pm 4$ & $37 \pm 4$ & $34 \pm 4$ \\
\hline FLUV & $34 \pm 3$ & $37 \pm 3$ & $32 \pm 2$ & $31 \pm 3$ & $30 \pm 2$ \\
\hline \multicolumn{6}{|c|}{ Hepatic sinusoidal glucagon, $n g / l$} \\
\hline SAL & $55 \pm 8$ & $52 \pm 5$ & $53 \pm 6$ & $51 \pm 5$ & $49 \pm 6$ \\
\hline FLUV & $38 \pm 5$ & $43 \pm 3$ & $41 \pm 2$ & $42 \pm 3$ & $41 \pm 3$ \\
\hline \multicolumn{6}{|c|}{ Arterial plasma cortisol, $\mathrm{nmol} / \mathrm{l}$} \\
\hline SAL & $75 \pm 15$ & $55 \pm 16$ & $50 \pm 8^{*}$ & $46 \pm 8^{*}$ & $65 \pm 6$ \\
\hline FLUV & $95 \pm 20$ & $88 \pm 8$ & $77 \pm 17 *$ & $64 \pm 7^{*}$ & $65 \pm 6^{*}$ \\
\hline \multicolumn{6}{|c|}{ Arterial plasma epinephrine, $\mathrm{pg} / \mathrm{ml}$} \\
\hline SAL & $112 \pm 31$ & $78 \pm 33$ & $47 \pm 21^{*}$ & $74 \pm 33$ & $75 \pm 39$ \\
\hline FLUV & $162 \pm 33$ & $105 \pm 21$ & $122 \pm 30$ & $96 \pm 33^{*}$ & $102 \pm 19 *$ \\
\hline \multicolumn{6}{|c|}{ Arterial plasma norepinephrine, $\mathrm{pg} / \mathrm{ml}$} \\
\hline SAL & $168 \pm 27$ & $154 \pm 33$ & $152 \pm 52$ & $177 \pm 39$ & $173 \pm 44$ \\
\hline FLUV & $184 \pm 39$ & $154 \pm 34$ & $156 \pm 25$ & $160 \pm 23$ & $151 \pm 25$ \\
\hline
\end{tabular}

Values are means \pm SE. SAL dogs $(n=9)$ received intraportal saline infusion during periods $(\mathrm{P}) 1-4$ (P1, 0-90 min; $\mathrm{P} 2,90-150 \mathrm{~min} ; \mathrm{P} 3,150-210$ $\mathrm{min}$; and $\mathrm{P} 4,210-270 \mathrm{~min})$; FLUV dogs $(n=8)$ received saline during $\mathrm{P} 1$ and intraportal fluvoxamine maleate at $0.5,1.0$, and $2.0 \mu \mathrm{g} \cdot \mathrm{kg}^{-1} \cdot \mathrm{min}^{-1}$, respectively, during P2-P4. Negative values indicate net hepatic uptake. There were no significant differences between groups. ${ }^{*} P<0.05$ vs. basal period. 5-HT, 5-hydroxytryptamine (serotonin).

$\mu \mathrm{mol} \cdot \mathrm{kg}^{-1} \cdot \mathrm{min}^{-1}$ in SAL and FLUV, respectively) and P2 $\left(14.4 \pm 2.6\right.$ and $15.5 \pm 2.5 \mu \mathrm{mol} \cdot \mathrm{kg}^{-1} \cdot \mathrm{min}^{-1}$, respectively; Fig. 2). Subsequently, the rate of NHGU remained relatively stable in SAL $\left(13.9 \pm 1.7\right.$ and $17.0 \pm 2.0 \mu \mathrm{mol} \cdot \mathrm{kg}^{-1} \cdot \mathrm{min}^{-1}$ in $\mathrm{P} 3$ and $\mathrm{P} 4$, respectively), whereas in FLUV it increased to $19.7 \pm 2.8$ and $26.6 \pm 3.0 \mu \mathrm{mol} \cdot \mathrm{kg}^{-1} \cdot \mathrm{min}^{-1}$ during $\mathrm{P} 3$ and P4, respectively $(P<0.05$ vs. SAL during both periods). Unidirectional (tracer-derived) hepatic glucose uptake revealed similar results $\left(\mu \mathrm{mol} \cdot \mathrm{kg}^{-1} \cdot \mathrm{min}^{-1}\right.$ in SAL and FLUV, respectively): $13.5 \pm 4.6$ vs. $22.2 \pm 4.7$ during $\mathrm{P} 3$ and $19.1 \pm 2.6$ vs. $26.3 \pm 4.5$ during $\mathrm{P} 4(P=0.08$ for both periods). The net hepatic fractional extraction of glucose followed a similar pattern, being significantly different between groups during P4 $(0.062 \pm 0.008$ and $0.089 \pm 0.010$ in SAL and FLUV, respectively; $P<0.05)$.
Table 2. Hepatic blood flow

\begin{tabular}{lccccc}
\hline \hline \multirow{2}{*}{$\begin{array}{c}\text { Blood Vessel } \\
\text { and Group }\end{array}$} & $\begin{array}{c}\text { Basal } \\
\text { Period }\end{array}$ & \multicolumn{5}{c}{ P1 } & P2 & P3 & P4 \\
\cline { 3 - 6 } & \multicolumn{5}{c}{ Hepatic artery } \\
SAL & $6.2 \pm 0.6$ & $8.4 \pm 1.1^{*}$ & $8.9 \pm 1.2^{*}$ & $9.4 \pm 1.4^{*}$ & $8.6 \pm 0.9^{*}$ \\
FLUV & $6.3 \pm 0.6$ & $7.1 \pm 0.5$ & $7.8 \pm 0.7^{*}$ & $8.2 \pm 0.8^{*}$ & $8.8 \pm 1.0^{*}$ \\
\multicolumn{5}{c}{ Portal vein } \\
SAL & $27.4 \pm 2.2$ & $22.8 \pm 1.8^{*}$ & $23.6 \pm 1.4^{*}$ & $23.7 \pm 1.2^{*}$ & $22.8 \pm 1.4^{*}$ \\
FLUV & $28.2 \pm 1.9$ & $22.4 \pm 1.2^{*}$ & $22.8 \pm 1.8^{*}$ & $22.3 \pm 1.2^{*}$ & $23.7 \pm 0.9^{*}$ \\
\hline
\end{tabular}

Values are means $\pm \mathrm{SE}$ in $\mathrm{ml} \cdot \mathrm{kg}^{-1} \cdot \mathrm{min}^{-1}$. There were no significant differences between groups. $* P<0.05$ vs. basal.

Glucose infusion rates, nonhepatic glucose uptake, glucose rate of appearance, and $R_{d}$. The glucose infusion rate in both groups increased steadily in a time-dependent manner during P1-P4 and did not differ between groups during any period (Fig. 3). Nonhepatic glucose uptake (non-HGU) increased over time in SAL $(26.1 \pm 2.9,36.1 \pm 3.0,45.7 \pm 4.5$, and $53.6 \pm$ $7.5 \mu \mathrm{mol} \cdot \mathrm{kg}^{-1} \cdot \mathrm{min}^{-1}$ during P1-P4, respectively). In FLUV, the non-HGU increased in a similar fashion during P1-P3, but in contrast to SAL, FLUV did not exhibit a significant increase in non-HGU between P3 and P4. The change in non-HGU between $\mathrm{P} 3$ and $\mathrm{P} 4$ was $8.0 \pm 4.0$ and $1.6 \pm 2.6$ $\mu \mathrm{mol} \cdot \mathrm{kg}^{-1} \cdot \mathrm{min}^{-1}$ in SAL and FLUV, respectively $(P=0.09$ between groups). Repeated-measures ANOVA indicated a significant group $\times$ time interaction, with the final time point being significantly different between groups. Muscle glycogen concentrations tended to be higher in FLUV than in SAL

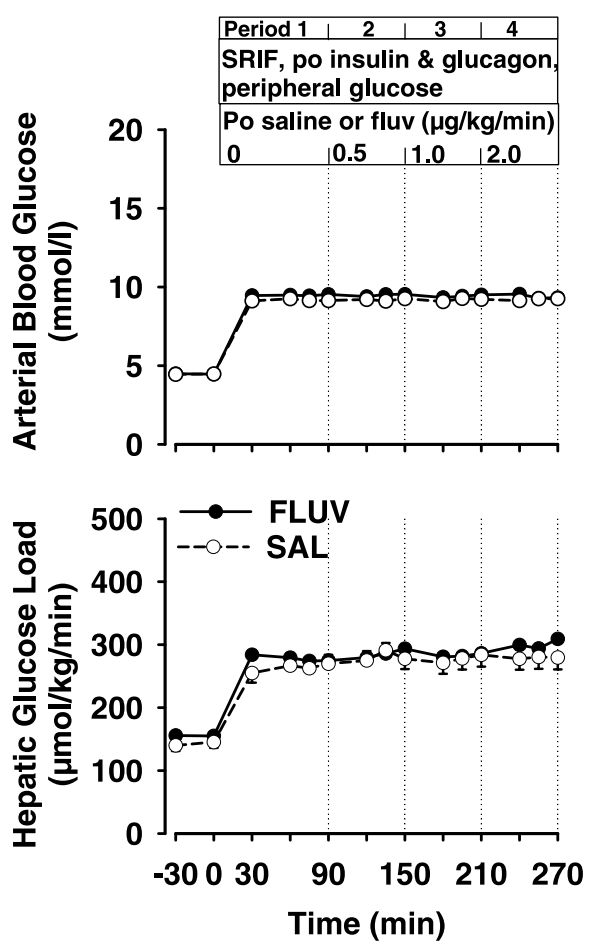

Fig. 1. Arterial blood glucose and hepatic glucose loads. SAL group $(n=9)$, receiving intraportal saline during periods $(\mathrm{P}) 1-4$ (P1, 0-90 min; $\mathrm{P} 2,90-150$ min; P3, 150-210 min; and P4, 210-270 min); FLUV group $(n=8)$, receiving intraportal fluvoxamine during P2-P4. Po, portal; SRIF, somatotropin releaseinhibiting factor. There were no significant differences between groups. 


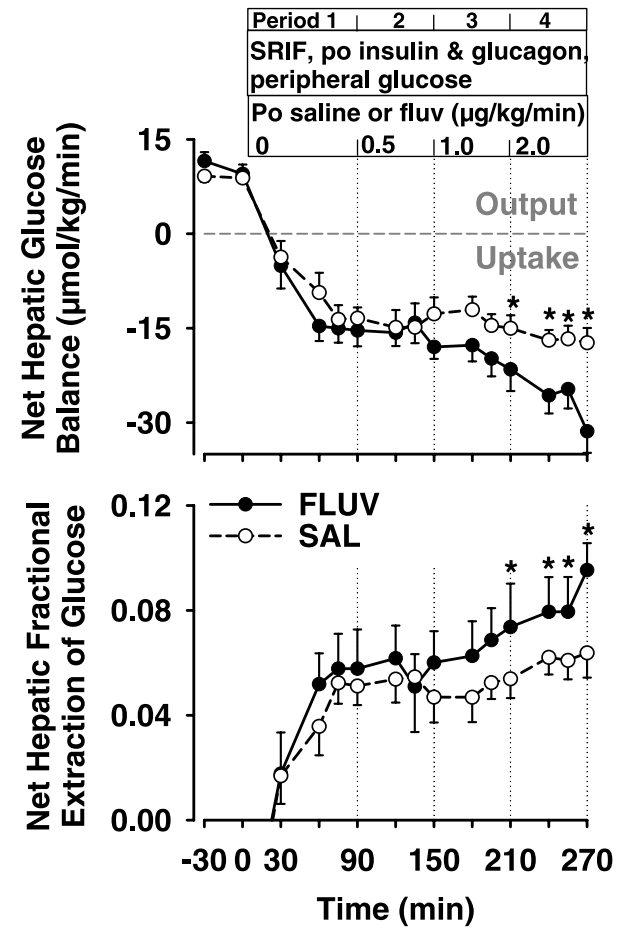

Fig. 2. Net hepatic glucose uptake and fractional extraction of glucose. See Fig. 1 for description of study conditions. ${ }^{*} P<0.05$ between groups.

$(12.9 \pm 0.6$ vs. $10.3 \pm 1.2 \mathrm{mg} / \mathrm{g}$ muscle in SAL and FLUV, respectively; $P=0.09$ ).

Endogenous glucose rate of appearance $\left(\mathrm{R}_{\mathrm{a}}\right)$ was suppressed to near zero in both groups and did not differ significantly between groups at any time (data not shown). Both groups

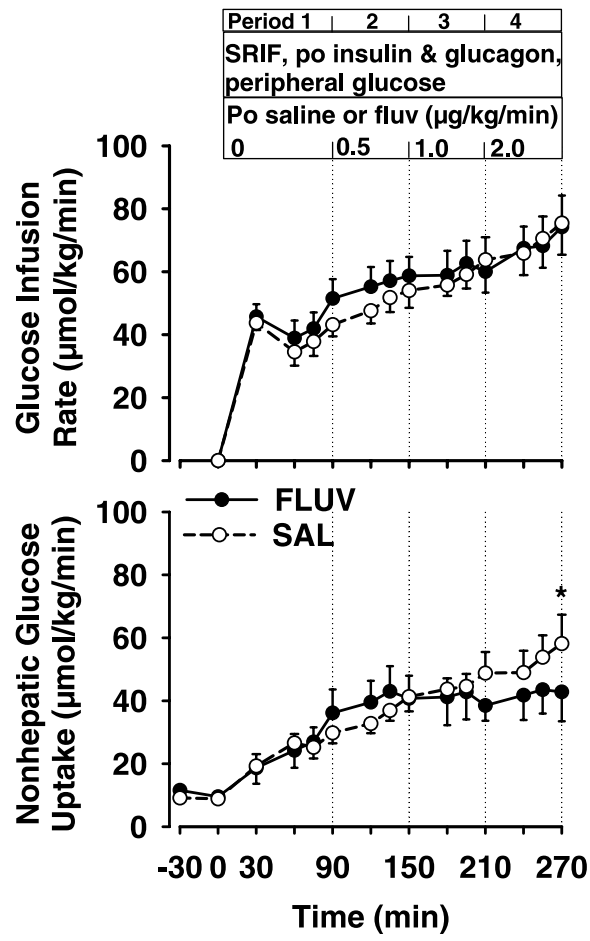

Fig. 3. Glucose infusion rate and nonhepatic glucose uptake. See Fig. 1 for description of study conditions. $* P<0.05$ between groups.
Table 3. Glucose disposal rate and arterial concentrations and net hepatic balances of lactate, glycerol, and NEFA

\begin{tabular}{|c|c|c|c|c|c|}
\hline \multirow[b]{2}{*}{ Group } & \multirow[b]{2}{*}{ Basal Period } & \multicolumn{4}{|c|}{ Experimental Period } \\
\hline & & P1 & P2 & P3 & P4 \\
\hline \multicolumn{6}{|c|}{ Glucose disposal rate, $\mu \mathrm{mol} \cdot \mathrm{kg}^{-1} \cdot \mathrm{min}^{-1}$} \\
\hline SAL & $13.2 \pm 0.3$ & $43.7 \pm 3.4$ & $53.9 \pm 4.5$ & $65.1 \pm 6.2$ & $79.9 \pm 9.6$ \\
\hline FLUV & $11.2 \pm 0.6$ & $44.3 \pm 4.6$ & $61.6 \pm 6.7$ & $65.0 \pm 6.2$ & $77.8 \pm 8.7$ \\
\hline \multicolumn{6}{|c|}{ Arterial blood lactate, $\mu \mathrm{mol} / \mathrm{l}$} \\
\hline SAL & $419 \pm 48$ & $862 \pm 110$ & $818 \pm 77$ & $902 \pm 62$ & $994 \pm 62$ \\
\hline FLUV & $587 \pm 94 *$ & $1192 \pm 106 *$ & $1073 \pm 61^{*}$ & $1005 \pm 64$ & $1086 \pm 50$ \\
\hline \multicolumn{6}{|c|}{ Net hepatic lactate balance, $\mu \mathrm{mol} \cdot \mathrm{kg}^{-1} \cdot \mathrm{min}^{-1}$} \\
\hline SAL & $-8.1 \pm 1.2$ & $6.5 \pm 1.7$ & $3.6 \pm 0.9$ & $2.7 \pm 1.1$ & $3.5 \pm 1.5$ \\
\hline FLUV & $-6.6 \pm 1.1$ & $10.3 \pm 2.5$ & $4.6 \pm 1.8$ & $3.9 \pm 1.4$ & $5.6 \pm 1.2$ \\
\hline \multicolumn{6}{|c|}{ Arterial blood glycerol, $\mu$ mol/l } \\
\hline SAL & $86 \pm 10$ & $42 \pm 10$ & $36 \pm 9$ & $38 \pm 9$ & $36 \pm 10$ \\
\hline FLUV & $91 \pm 12$ & $30 \pm 3$ & $32 \pm 4$ & $27 \pm 5$ & $27 \pm 3$ \\
\hline \multicolumn{6}{|c|}{ Net hepatic glycerol uptake, $\mu \mathrm{mol} \cdot \mathrm{kg}^{-1} \cdot \mathrm{min}^{-1}$} \\
\hline SAL & $1.9 \pm 0.4$ & $0.8 \pm 0.3$ & $0.7 \pm 0.2$ & $0.7 \pm 0.3$ & $0.7 \pm 0.3$ \\
\hline FLUV & $1.8 \pm 0.2$ & $0.6 \pm 0.2$ & $0.5 \pm 0.1$ & $0.5 \pm 0.1$ & $0.4 \pm 0.0$ \\
\hline \multicolumn{6}{|c|}{ Arterial plasma NEFA, $\mu \mathrm{mol} / \mathrm{l}$} \\
\hline SAL & $865 \pm 76$ & $102 \pm 17$ & $91 \pm 12$ & $83 \pm 13$ & $88 \pm 19$ \\
\hline FLUV & $798 \pm 66$ & $167 \pm 23 *$ & $142 \pm 20^{*}$ & $107 \pm 22$ & $95 \pm 13$ \\
\hline \multicolumn{6}{|c|}{ Net hepatic NEFA uptake, $\mu \mathrm{mol} \cdot \mathrm{kg}^{-1} \cdot \mathrm{min}^{-1}$} \\
\hline SAL & $3.2 \pm 0.8$ & $0.3 \pm 0.2$ & $0.2 \pm 0.1$ & $0.2 \pm 0.1$ & $0.2 \pm 0.1$ \\
\hline FLUV & $2.3 \pm 0.3$ & $0.3 \pm 0.1$ & $0.4 \pm 0.1$ & $0.2 \pm 0.1$ & $0.4 \pm 0.1$ \\
\hline
\end{tabular}

Values are means \pm SE. For nonesterified fatty acid (NEFA) data only, $n=$ 7 for both groups. Negative values for balance indicate net hepatic uptake; rates of net hepatic uptake are shown as positive values for substrates for which there was no net release by the liver. $* P<0.05$ vs. SAL.

demonstrated progressive increases in glucose $\mathrm{R}_{\mathrm{d}}$ during P1$\mathrm{P} 4$, and there were no significant differences between groups at any time (Table 3$)$.

Lactate metabolism, net hepatic carbon retention, and hepatic glycogen concentrations. The arterial blood lactate concentrations were higher in the FLUV group than in SAL during the basal period and $\mathrm{P} 1-\mathrm{P} 2$, but the concentrations did not differ between groups during P3-P4 (Table 3). After the experimental period began, net hepatic lactate balance changed

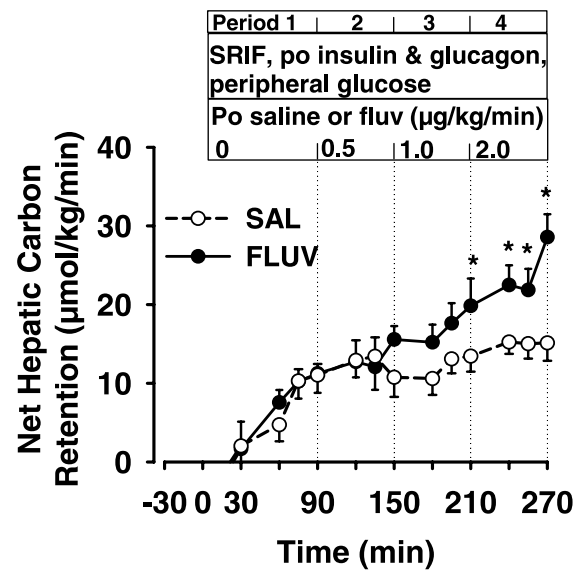

Fig. 4. Net hepatic carbon retention. See Fig. 1 for description of study conditions. $* P<0.05$ between groups. 
from uptake to output in both groups, and the rates did not differ between groups during any period.

Net hepatic carbon retention did not differ in FLUV and SAL during P1-P2 (Fig. 4). However, net hepatic carbon retention was enhanced $(P<0.05)$ by fluvoxamine during P3 $\left(12.0 \pm 1.8\right.$ vs. $17.6 \pm 2.6 \mu \mathrm{mol} \cdot \mathrm{kg}^{-1} \cdot \mathrm{min}^{-1}$, SAL vs. FLUV $)$ and P4 (15.2 \pm 1.8 vs. $\left.23.7 \pm 2.6 \mu \mathrm{mol} \cdot \mathrm{kg}^{-1} \cdot \mathrm{min}^{-1}\right)$. Similarly, the hepatic glycogen concentrations at the end of study were $50 \%$ greater in FLUV than in SAL (6.3 \pm 0.6 vs. $4.2 \pm 0.4 \mathrm{~g} / 100 \mathrm{~g}$ liver, $P<0.005$ ).

Glycerol and nonesterified fatty acid metabolism. Arterial glycerol concentrations and net hepatic glycerol uptake were reduced $\sim 65-75 \%$ by hyperglycemia and hyperinsulinemia (Table 3) and remained suppressed in both groups throughout $\mathrm{P} 1-\mathrm{P} 4$. Arterial nonesterified fatty acid (NEFA) concentrations and net hepatic NEFA uptake changed in a manner similar to glycerol, decreasing $80-90 \%$ during P1 in both groups and remaining low for the duration of the experimental period. Arterial NEFA concentrations declined more slowly in the FLUV group than in the SAL group, but the groups had reached similar levels by P3.

\section{DISCUSSION}

A twofold increase in the hepatic glucose load in the presence of fourfold basal insulin and basal glucagon concentrations resulted in an NHGU of $\sim 13-15 \mu \mathrm{mol} \cdot \mathrm{kg}^{-1} \cdot \mathrm{min}^{-1}$ in the two groups. During infusion of fluvoxamine at 0.5 $\mu \mathrm{g} \cdot \mathrm{kg}^{-1} \cdot \mathrm{min}^{-1}$, there was no enhancement in NHGU compared with SAL. However, during fluvoxamine infusion at 1.0 and $2.0 \mu \mathrm{g} \cdot \mathrm{kg}^{-1} \cdot \mathrm{min}^{-1}$, NHGU was 42 and $57 \%(P<0.05$ for both), respectively, greater than the corresponding rates in SAL. Similar to NHGU, net hepatic carbon retention was virtually identical between the groups during P1 and P2. The enhancement of NHGU was accompanied by an increase in net hepatic carbon retention in the FLUV group (47 and 56\% greater in FLUV than in SAL during P3 and P4, respectively, $P<0.05)$, as well as a $50 \%$ increment $(P<0.005)$ in the hepatic glycogen content at the end of study.

In this initial study, we were primarily interested in determining whether fluvoxamine, administered intraportally at any dosage, was capable of stimulating NHGU in a situation mimicking postprandial hormonal and glycemic conditions. Thus we administered fluvoxamine in three increasing steps during P2-P4, and it is not possible to separate the effects of time from those of dosage. Nevertheless, it is possible to conclude that fluvoxamine impacted NHGU positively and that the net result was not a stimulation of glycolysis but instead an increase in hepatic carbon storage. In future studies, we will address the time course of the hepatic response to a single fluvoxamine infusion rate.

The enhancement of net hepatic carbon retention in the present studies contrasts with findings in sham-operated or $90 \%$-pancreatectomized rats given fluoxetine orally for $8 \mathrm{wk}$. In the rat studies, the SSRI did not increase hepatic glycogen deposition; although it tended to increase hepatic glucose uptake in both sham and diabetic animals, this did not reach statistical significance. Instead, fluoxetine significantly enhanced skeletal muscle glucose uptake and glycogen deposition while reducing intramuscular triglyceride content (28). The difference between our findings and those in the rat may reflect the difference between acute and chronic SSRI administration, a difference in dosages $(5 \mathrm{mg} / \mathrm{kg}$ in the rat, equivalent to $\sim 16$ times the daily therapeutic dose in the human and much greater in relative terms than the amount infused in the dog), or differences in fluoxetine and fluvoxamine action. With regard to the latter possibility, acute administration of fluoxetine and fluvoxamine to mice produced virtually identical effects on blood glucose at equal dosages. However, fluvoxamine's effects could be blocked by the 5-HT-depleting agent $p$-chlorophenylalanine methyl ester hydrochloride, whereas the effects of fluoxetine could not, suggesting that the glycemic effects of the two SSRIs occur via different mechanisms (38).

The magnitude of the increases in NHGU and net hepatic carbon retention during infusion of fluvoxamine at 2 $\mu \mathrm{g} \cdot \mathrm{kg}^{-1} \cdot \mathrm{min}^{-1}$ was similar to those we observed during intraportal infusion of 5-HT at $40 \mu \mathrm{g} \cdot \mathrm{kg}^{-1} \cdot \mathrm{min}^{-1}$. Fluvoxamine does not stimulate release of endogenous 5-HT but instead delays its reuptake into the presynaptic nerve endings. The effects of fluvoxamine on the liver could have resulted either from enhancement of a direct effect of endogenous 5-HT on the hepatocytes or as a result of a secondary signal initiated elsewhere. With regard to a potential direct effect of 5-HT on hepatocytes, the $5-\mathrm{HT}_{2 \mathrm{~B}}$ receptor is known to be expressed in greatest abundance in the liver and kidney in humans (6). With regard to the second possibility, Niijima (25) determined that intraportal injection of 5-HT resulted in a decrease in the afferent firing rate in the hepatic branch of the vagus nerve and a stimulation of efferent firing in the pancreatic branch of the vagus, similar to the effect of intraportal glucose injection (24), suggesting a mechanism by which 5-HT in the hepatoportal region could elicit a neural signal to enhance NHGU. Alternatively, fluvoxamine itself could have a direct effect on the liver. Although this possibility is suggested by the fact that net hepatic 5-HT output did not increase during fluvoxamine infusion, net hepatic balance is not likely to be a sensitive measure of the output of a neurotransmitter that can undergo both release and extraction within a single organ $(2,5)$.

At the highest infusion rate, fluvoxamine reduced glucose uptake in the nonhepatic tissues $\sim 25 \%$ compared with the corresponding rate in SAL (although post hoc analysis indicated that only the last time point was statistically different). This decrease offset the increase in NHGU so that total body glucose disposal was the same between groups, as evidenced by the comparable glucose infusion rates and glucose $R_{d}$ in the two groups. We observed a blunting of non-HGU during the infusion of 5-HT as well (22), but in those studies the circulating catecholamine concentrations rose significantly with the higher rates of infusion and might have been responsible for reducing non-HGU. However, there were no elevations in circulating catecholamine concentrations observed in response to fluvoxamine infusion. It is possible that fluvoxamine, acting at target sites in peripheral tissues, had a direct effect to reduce glucose uptake by skeletal muscle, the primary insulin-sensitive peripheral tissue in the dog. This explanation seems unlikely, however. We infused the fluvoxamine directly into the portal circulation at a low rate; oral doses of the drug undergo extensive first-pass extraction by the liver, the major route of elimination, and numerous metabolites of fluvoxamine are produced, none of which is believed to be active (16). Alternatively, the tendency toward reduction of non-HGU with the highest rate of fluvoxamine infusion might have resulted 
from a secondary effect of 5-HT. Circulating concentrations of 5-HT did not rise, but it is conceivable that local concentrations in the skeletal muscle were elevated secondary to a centrally mediated reflex. 5-HT is reported to have either no effect (30) or a stimulatory effect (14) on glucose uptake in isolated skeletal muscle. However, it has vasoactive effects in skeletal muscle in vivo, causing the channeling of blood away from the vessels supplying oxygen and nutrients to skeletal muscle ("nutritive flow") and into other vessels (those supplying connective tissue and associated adipocytes, creating "nonnutritive flow") and reducing muscle and hindlimb nutrient uptake (8, $30)$. Finally, it is worth noting that our laboratory $(1,17,18)$ has previously observed a reciprocal relationship between hepatic and peripheral glucose uptake, such that when NHGU is stimulated by the presence of the "portal signal," there is a concomitant decrease in non-HGU. Thus the presence of an integrated mechanism for partitioning glucose disposal among the tissues in the postprandial state may explain the tendency toward suppression of non-HGU concomitant with stimulation of NHGU in the FLUV group. The glycogen concentrations in the single skeletal muscle examined actually tended to be higher $(\sim 30 \%)$ in FLUV than in SAL, suggesting that a process other than glucose storage might be affected by fluvoxamine.

There was a tendency (not statistically significant) for epinephrine to be higher in the FLUV group throughout the study and for cortisol concentrations to be higher in the basal period and in P1-P3. However, there is no evidence that fluvoxamine stimulated adrenal hormone release, as the concentrations of cortisol and epinephrine tended to be higher in the FLUV group during the basal and P1 periods, when there was no difference in treatment of the two groups. Moreover, the concentrations of these hormones declined over the course of the study in both groups, with FLUV exhibiting a greater decline than SAL. Although chronic elevation of cortisol stimulates NHGU, short-term (similar to the duration of the current studies) cortisol elevation has no discernible impact on NHGU (13). The direct effect of epinephrine on the liver is to stimulate glycogenolysis (7); thus, to the extent that a physiological differential in concentrations existed between FLUV and SAL, it would have minimized any difference in NHGU between the groups. Thus there is little risk that the tendency of cortisol and epinephrine to be higher in the FLUV group was responsible for the enhancement of NHGU we observed in that group.

Other than a possible role in inhibition of peripheral glucose uptake, fluvoxamine had no apparent systemic effects. In contrast to intraportal 5-HT delivery, which was accompanied by a marked stimulation of lipolysis, as evidenced by increased glycerol and NEFA concentrations, lipolysis was suppressed similarly in the FLUV and SAL groups. Thus the lipolytic response evident during 5-HT infusion (22) was likely due to the increases in catecholamine release. Alternatively, the high circulating levels of 5-HT achieved during intraportal 5-HT infusion may have had direct lipolytic effects.

In conclusion, intraportal infusion of fluvoxamine enhanced NHGU under hyperglycemic hyperinsulinemic conditions. At the same time, it brought about an offsetting decrease in non-HGU so that total body glucose disposal was not different than in control dogs. During fluvoxamine infusion, there were no elevations of stress hormones such as we had observed during 5-HT infusion. No gastrointestinal side effects of fluvoxamine were observed. Taken together with our previous work (22) and data from the mouse (10), these findings indicate that 5-HT can play a role in directing glucose into the liver and stimulating its storage there. That these effects are seen with an SSRI, with no acute adverse effects and no differences between groups in insulin concentrations, suggests that compounds that can raise endogenous hepatic serotonin concentrations [specifically, a hepatic-targeted agent with SSRI-like activity (12)] might have a role in reducing postprandial hyperglycemia in individuals with type 2 diabetes.

\section{ACKNOWLEDGMENTS}

We thank Jon Hastings, Tiffany Rodewald, and the members of the Vanderbilt Diabetes Research and Training Center Hormone Core Lab (Wanda Snead, Angelina Penaloza, and Eric Allen) for assistance with this project.

\section{GRANTS}

This work was supported by a Research Award from the American Diabetes Association to M. C. Moore, by National Institute of Diabetes and Digestive and Kidney Diseases Grant DK-43706, and by Diabetes Research and Training Center Grant SP-60-AM-20593. The serotonin analyses were performed by the Center for Molecular Neuroscience Neurochemistry Core, supported in part by National Institute of Child Health and Human Development Grant P30-HD15022, managed by Raymond Johnson.

\section{REFERENCES}

1. Adkins BA, Myers SR, Hendrick GK, Stevenson RW, Williams PE, and Cherrington AD. Importance of the route of intravenous glucose delivery to hepatic glucose balance in the conscious dog. J Clin Invest 79: 557-565, 1987.

2. Ahren B, Dunning BE, Havel PJ, Veith RC, and Taborsky GJ Jr. Extraction of epinephrine and norepinephrine by the dog pancreas in vivo. Metabolism 37: 68-73, 1988.

3. Anthony M. Serotonin antagonists. Aust NZ J Med 14: 888-895, 1984.

4. Bearcroft CP, Perrett D, and Farthing MJ. Postprandial plasma 5-hydroxytryptamine in diarrhoea predominant irritable bowel syndrome: a pilot study. Gut 42: 42-46, 1998.

5. Blombery PA and Heinzow BG. Cardiac and pulmonary norepinephrine release and removal in the dog. Circ Res 53: 688-694, 1983.

6. Bonhaus DW, Bach C, DeSouza A, Salazar FHR, Matsuoka BD, Zuppan P, Chan HW, and Eglen RM. The pharmacology and distribution of human 5-hydroxytryptamine $2 \mathrm{~B}\left(5-\mathrm{HT}_{2 \mathrm{~B}}\right)$ receptor gene products: comparison with $5-\mathrm{HT}_{2 \mathrm{~A}}$ and $5-\mathrm{HT}_{2 \mathrm{C}}$ receptors. $\mathrm{Br} \mathrm{J}$ Pharmacol 115: 662-628, 1995.

7. Chu CA, Sindelar DK, Neal DW, Allen EJ, Donahue EP, and Cherrington AD. Comparison of the direct and indirect effects of epinephrine on hepatic glucose production. J Clin Invest 99: 1044-1056, 1997.

8. Clerk LH, Smith ME, Rattigan S, and Clark MG. Nonnutritive flow impairs uptake of fatty acid by white muscles of the perfused rat hindlimb. Am J Physiol Endocrinol Metab 284: E611-E617, 2003.

9. Cowan JS and Hetenyi G Jr. Glucoregulatory responses in normal and diabetic dogs recorded by a new tracer method. Metabolism 20: 360-372, 1971

10. Endo Y. Evidence that the accumulation of 5-hydroxytryptamine in the liver but not in the brain may cause the hypoglycaemia induced by 5-hydroxytryptophan. Br J Pharmacol 85: 591-598, 1985.

11. Erenmemisoglu A, Ozdogan UK, Saraymen R, and Tutus A. Effect of some antidepressants on glycaemia and insulin levels of normoglycaemic and alloxan-induced hyperglycaemic mice. J Pharm Pharmacol 51: 741743, 1999.

12. Geho WB and Lau JR. Hepatocyte Directed Vesicle Delivery System. US Patent No. 4,603,044. In: U.S. Patent Office. USA: Technology Unlimited, 1986.

13. Goldstein RE, Reed GW, Wasserman DH, Williams PE, Lacy DB, Buckspan R, Abumrad NN, and Cherrington AD. The effects of acute elevations in plasma cortisol levels on alanine metabolism in the conscious dog. Metabolism 41: 1295-1303, 1992.

14. Hajduch E, Rencurel F, Balendran A, Batty IH, Downes CP, and Hundal HS. Serotonin (5-hydroxytryptamine), a novel regulator of glu- 
cose transport in rat skeletal muscle. J Biol Chem 274: 13563-13568, 1999.

15. Hendrick GK, Frizzell RT, Williams PE, and Cherrington AD. Effect of hyperglucagonemia on hepatic glycogenolysis and gluconeogenesis after a prolonged fast. Am J Physiol Endocrinol Metab 258: E841-E849, 1990.

16. Hiemke $\mathbf{C}$ and Hartter $\mathbf{S}$. Pharmacokinetics of selective serotonin reuptake inhibitors. Pharmacol Ther 85: 11-28, 2000.

17. Hsieh PS, Moore MC, Neal DW, Emshwiller M, and Cherrington AD. Rapid reversal of the effects of the portal signal under hyperinsulinemic conditions in the conscious dog. Am J Physiol Endocrinol Metab 276: E930-E937, 1999.

18. Hsieh PS, Moore MC, Neal DW, Venson P, and Cherrington AD. Hepatic glucose uptake rapidly decreases after elimination of the portal signal in conscious dogs. Am J Physiol Endocrinol Metab 275: E987E992, 1998.

19. Jackson RA, Hamling JB, Sim BM, Hawa MI, Blix PM, and Nabarro JD. Peripheral lactate and oxygen metabolism in man: the influence of oral glucose loading. Metabolism 36: 144-150, 1987.

20. Jackson RA, Roshania RD, Hawa MI, Sim BM, and DiSilvio L. Impact of glucose ingestion on hepatic and peripheral glucose metabolism in man: an analysis based on simultaneous use of the forearm and double isotope techniques. J Clin Endocrinol Metab 63: 541-549, 1986.

21. Keppler D and Decker K. Glycogen: determination with amyloglucosidase. In: Methods in Enzymatic Analysis, edited by Bergmeyer HU. New York: Verlag Chemie Weinheim/Academic, 1974, p. 1127-1131.

22. Moore MC, Geho WB, Lautz M, Farmer B, Neal DW, and Cherrington AD. Portal serotonin infusion and glucose disposal in conscious dogs. Diabetes 53: 14-20, 2004.

23. Myers SR, Biggers DW, Neal DW, and Cherrington AD. Intraportal glucose delivery enhances the effects of hepatic glucose load on net hepatic glucose uptake in vivo. J Clin Invest 88: 158-167, 1991.

24. Niijima A. Afferent impulse discharges from glucoreceptors in the liver of the guinea pig. Ann NY Acad Sci 157: 690-700, 1969.

25. Niijima A. Visceral afferents and metabolic function. Diabetologia 20, Suppl: 325-330, 1981.

26. Nishizawa M, Moore MC, Shiota M, Gustavson SM, Snead WL, Neal DW, and Cherrington AD. Effect of intraportal glucagon-like peptide-1 on glucose metabolism in conscious dogs. Am J Physiol Endocrinol Metab 284: E1027-E1036, 2003.
27. Pagliassotti MJ, Holste LC, Moore MC, Neal DW, and Cherrington AD. Comparison of the time courses of insulin and the portal signal on hepatic glucose and glycogen metabolism in the dog. J Clin Invest 97: 81-91, 1996.

28. Park S and Choi SB. Does fluoxetine administration influence insulin resistance in 90\% pancreatectomized rats? Metabolism 51: 38-43, 2002.

29. Pussard E, Guigueno N, Adam O, and Giudicelli JF. Validation of HPLC-amperometric detection to measure serotonin in plasma, platelets, whole blood, and urine. Clin Chem 42: 1086-1091, 1996.

30. Rattigan S, Dora KA, Colquhoun EQ, and Clark MG. Serotoninmediated acute insulin resistance in the perfused rat hindlimb but not in incubated muscle: a role for the vascular system. Life Sci 53: 1545-1555, 1993.

31. Satake S, Moore MC, Igawa K, Converse M, Farmer B, Neal DW, and Cherrington AD. Direct and indirect effects of insulin on glucose uptake and storage by the liver. Diabetes 51: 1663-1671, 2002.

32. Steele R, Wall JS, DeBodo RC, and Altszuler N. Measurement of size and turnover rate of body glucose pool by the isotope dilution method. Am J Physiol 187: 15-24, 1956.

33. Sussman N, Ginsberg DL, and Bikoff J. Effects of nefazodone on body weight: a pooled analysis of selective serotonin reuptake inhibitor- and imipramine-controlled trials. J Clin Psychiatry 62: 256-260, 2001.

34. Tatsumi M, Groshan K, Blakely RD, and Richelson E. Pharmacological profile of antidepressants and related compounds at human monoamine transporters. Eur J Pharmacol 340: 249-258, 1997.

35. United Kingdom Prospective Diabetes Study Group. Intensive bloodglucose control with sulphonylureas or insulin compared with conventional treatment and risk of complications in patients with type 2 diabetes (UKPDS 33). Lancet 352: 837-853, 1998.

36. Van Harten J. Overview of the pharmacokinetics of fluvoxamine. Clin Pharmacokinet 29: 1-9, 1995.

37. Wieczorek I, Schulz C, Jarry H, and Lehnert H. The effects of the selective serotonin reuptake-inhibitor fluvoxamine on body weight in Zucker rats are mediated by corticotropin-releasing hormone. Int J Obes Relat Metab Disord 25: 1566-1569, 2001.

38. Yamada J, Sugimoto Y, and Inoue K. Selective serotonin reuptake inhibitors fluoxetine and fluvoxamine induce hyperglycemia by different mechanisms. Eur J Pharmacol 382: 2111-2215, 1999. 